\title{
The Peterborough lorry explosion, 22 March 1989: An analysis of the hospital
}

\section{response}

G. W. L. EVANS, B. ISGAR, W. BRUINS, J. R. GLOVER

Peterborough District Hospital, Peterborough

\section{SUMMARY}

As a result of the lorry explosion on the Fengate Industrial Estate, Peterborough on 22nd March 1989, 82 casualties arrived at Peterborough District Hospital. Despite the fact that casualties arrived at the A\&E Department in large numbers before the Major Accident Plan could be implemented, all of the casualties had been assessed and either admitted or sent home within $3 \mathrm{~h}$ of the explosion. In the process several valuable lessons were learned, and their implications are discussed in this paper.

\section{INTRODUCTION}

The Major Accident Plan for Peterborough District Hospital is typical of most such plans in the UK, in that it envisages the controlled flow of patients through a single, previously designated entrance; triage of those patients at the entrance, and subsequent assignment of each patient to the appropriate hospital department according to triage category, e.g. resuscitation area, operating theatre, surgical ward, minor injuries area etc.

However, this plan relies on a period of delay between the initial alert and the arrival of the first casualties at the hospital.

Correspondence: Mr G. W. L. Evans FRCS Ed, Tutor in Accident \& Emergency Medicine, AEE Department, St James's University Hospital, Beckett Street, Leeds LS9 7TF 


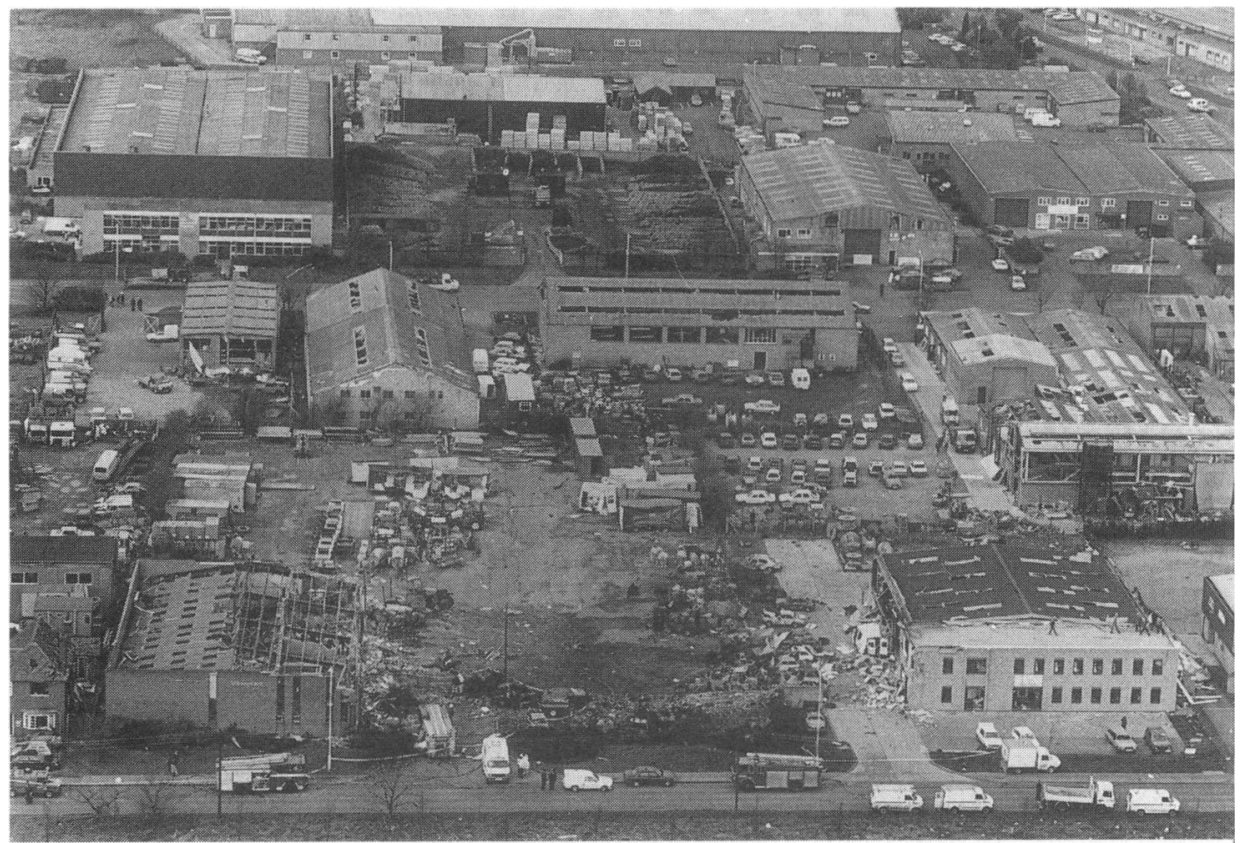

Fig. 1. The scene of the Peterborough lorry explosion

\section{THE INCIDENT}

At 09.36 on Wednesday, 22nd March, 1989, firemen in three appliances responded to a fire in a lorry on the Fengate Industrial Estate, Peterborough.

Passers-by and workers in adjacent buildings were watching the scene when at 09.47 the lorry exploded, killing one fireman instantly. The surrounding buildings and vehicles were devastated (Fig. 1). The lorry had been carrying explosives and detonators. Many of the latter were scattered over a wide area, causing problems in site clearance for several days afterwards.

Contact between the Emergency Services and the scene was lost, as the explosion destroyed the radio equipment in the fire appliances, so it was some time before a co-ordinated response to the incident could be organized.

\section{THE HOSPITAL RESPONSE}

Some confused radio messages between Ambulances going to the scene and their control were overheard by the A\&E staff, as there is a radio link between the A\&E Department and the Ambulance Service. However, no definite information about the incident was received. By $10.00 \mathrm{~h}$ over 20 patients had arrived at the A\&E 
Department by their own transport. Most of these patients had apparently suffered only minor injuries, but were emotionally shocked by the event, and although the information they provided suggested many more casualties would be arriving, they could give no coherent account of what had happened.

At this stage the Major Accident Plan was implemented by the Registrar in Accident and Emergency. The A\&E Consultant was on leave, so the Duty Consultant Physician became the Co-ordinating Medical Officer. Medical, Nursing and Administrative staff were alerted by the Hospital Switchboard following lists prepared as part of the plan. Outpatient clinics were discontinued and the Outpatient entrance foyer cleared for use as a Triage and documentation area next to the Incident Control Point. Two clinic areas were set aside and staffed for the treatment of minor injuries.

By now virtually all the patients so far received, together with most of the extra staff alerted, had been gathered in the A\&E Department, which was in danger of grinding to a halt from over-crowding. As a matter of urgency the A\&E Department was cleared of all but the most serious cases; and Medical and Nursing staff were directed to the Control point for re-allocation. Meanwhile two surgical wards were cleared, routine operating lists were discontinued, and the Intensive Care Unit and Blood Bank put on 'stand-by' to deal with an unknown number of seriously injured patients.

With no accurate information from the scene, we assumed the worst. It seemed likely that we had so far received only the minor casualties from the periphery of the blast, and that more seriously injured victims were still being dug from the rubble. At $10.30 \mathrm{~h}$ approximately the Senior Nursing Officer in A\&E managed to contact Ambulance Control and ask if they needed a Mobile Surgical Team at the scene. Ambulance Control gave no definite answer, so a Mobile Team (Surgical Registrar, Anaesthetic Registrar and Staff Nurse) was sent. At the scene they established from the Senior police and Fire Officers that all the seriously injured had already been dispatched to the hospital. Several patients with minor injuries were being treated at the scene by General Practitioners from the Mid-Anglia G.P. Accident Service (MAGPAS). The Mobile Team therefore returned to the hospital and gave the first accurate report from the scene to the Co-ordinating Medical Officer.

At 12.35 the last patient from the initial influx of casualties was treated for minor cuts and discharged home. In total 60 patients had been documented through the A\&E Department and 22 through the Triage in Outpatients in less than $3 \mathrm{~h}$ after the explosion.

\section{DETAILS OF CASUALTIES}

One casualty, a Leading Fireman who had been close to the blast, was dead on arrival; post-mortem examination showed death was due to a metal fragment entering the brain; there was also diffuse lung injury.

Twelve patients required admission; 69 were allowed home after treatment. Two 
firemen who were initially allowed back to duty were subsequently admitted, on for post-concussion headache which got worse later that day; the other two day later for removal of a glass fragment from his neck which had been missed on? initial examination.

One patient with a penetrating chest injury was admitted directly to the Inల tensive Care Unit for stabilization; X-ray showed a metal fragment in the righ lung. At thoracotomy later that day the fragment was removed. Blast fragments are high velocity missiles, and so the wound was packed open and closed by delay primary suture 5 days later in accordance with standard principles (Owen-Smith 1981).

Another patient with a history of previous coronary artery by-pass operation $\overrightarrow{\mathrm{W}}$ was admitted directly to the Intensive Care Unit with suspected myocardial in farction. This subsequently appeared unlikely so he was transferred later that dae. to a medical ward for observation, and discharged 2 days later.

A fireman with $10 \%$ partial-thickness burns developed respiratory problems or the Surgical Ward and had to be transferred to ICU several hours after admission Review of his case notes suggest that this deterioration might have been an은 ticipated on admission, as there were signs suggesting that airway burns were likely. However, he eventually made a full recovery.

Five patients were admitted to the General Surgical Ward for observation follow ing head or abdominal injuries; all were discharged within $48 \mathrm{~h}$.

Two patients were admitted for eye injuries - one required operative remoyal of glass fragments, the other had bilateral hyphaemas.

Two patients required Orthopaedic admission, one with multiple lumbar trass: verse process fractures, the other for further assessment of a neck injury with suspicious X-ray appearances. Acute bony injury or dislocation was later ruled ouf and he was discharged next day.

Seventeen patients complained of hearing loss or tinnitus; eight of these had tympanic perforations (seven bilateral). All of these patients have been followe $\vec{\Phi}$ up by the ENT department. Another patient attended the A\&E Department nex day complaining of tinnitus, and was referred to ENT. It is believed that severaf other patients have been treated for these complaints by their GP's.

In addition, several patients attended the A\&E Department over the next few. days with minor cuts which they had not wanted to bother the hospital with org the day of the disaster.

All patients had been discharged from hospital by 3 weeks after the explosion $\frac{0}{\not}$ with no further fatalities.

Further follow-up was confined to patients with hearing problems and a smali number with burns and facial lacerations requiring plastic or maxillo-facial surgica黑. review.

DISCUSSION

Of the 81 casualties who arrived alive at Peterborough District Hospital only 
$12(14.8 \%)$ required hospital admission; this figure is similar to that of $16 \%$ found by Hadden (1978) in a major review of blast injuries.

The relatively large proportion of minor injuries is typical of explosions which occur in the open air. In a review of 495 deaths from 5600 bomb blasts in Northern Ireland, Hill found that $75 \%$ of deaths occurred in a confined area (building or vehicle) Hill, 1979). 'Blast Lung' syndrome was not evident among the Peterborough casualties, and is indeed rare after open-air explosions (Coppel, 1976), but the possibility must be considered if the diagnosis is not to be delayed. Although the signs of blast lung usually appear within $4 \mathrm{~h}$ of the blast (Caseby and Porter, 1976), they sometimes do not appear for up to two days (Gray and Coppe, 1975).

Assessment of minor injuries takes almost as long as that of major injuries, as the possibility of occult injury and delayed complications (e.g. blast lung) must be borne in mind. Moreover, treatment and follow-up must be arranged at the time if patients are to be allowed home. In deciding to designate an incident as 'major' the numbers of patients involved is therefore more important than the severity of their injuries.

The arrival of casualties before the Major Accident Plan could be implemented is not unique; similar problems occurred in the Old Bailey bombing in 1973 (Caro \& Irving, 1973) and after the Bradford Football Stadium Fire (Sharpe et al., 1985). This should be appreciated in the design of Major Accident Plans, and such a scenario might usefully be included in Major Accident exercises.

Inevitably, some staff were used in the A\&E Department who had no previous $A \& E$ experience. Although their help was welcome, their unfamiliarity with the department, equipment and documentation increased the general level of confusion. Some of the errors that were made may be attributed to lack of A\&E experience. Many errors can be reduced by having experienced second-opinions on hand. The presence of Consultant Surgeons, Anaesthetists and Physicians in the Triage and $\mathrm{A} \& \mathrm{E} /$ Resuscitation areas was most useful, and a Consultant Radiologist issuing 'hot' hand-written X-ray reports on the $41 \mathrm{X}$-rays carried out during the incident was extremely valuable.

The Peterborough plan relied heavily on lines of communication being established at the outset by an orderly 'call-out', thus minimizing subsequent use of the switchboard once everyone was in place. This did not happen, as the incident was almost over before everyone was in place. The burden on the switchboard operators was thus greatly increased, and although they coped admirably the need for alternative methods (e.g. walkie-talkies, messengers, use of pay phones etc.) was apparent. The switchboard received 1500 calls in the afternoon and evening following the incident.

This incident showed that a Major Accident Plan is not a 'fire-and-forget' missile, to be started then allowed to run its course. As the situation changes the plan will need to be adapted; for example, our plan did not envisage calling in the maxillo-facial Consultants; many of the patients had minor facial injuries which could have been assessed more quickly had this expert help been utilized.

Finally it should be re-iterated that patients require continual re-assessment. Initial rapid assessment in the Triage area may not 'pick-up' all of a patient's injuries or problems; nor are Triage categories designed to be permanent. 


\section{CONCLUSIONS}

The two most important lessons learned from this incident were:

(1) Patients will arrive before the Major Accident Plan is implemented and;

(2) The reception, assessment and documentation of patients is best done by staff who have done it before.

\section{REFERENCES}

Caro D. \& Irving M. (1973) 'The Old Bailey Bomb Explosion'. Lancet, 1433-5.

Caseby N. G. \& Porter M. F. (1976) 'Blast Injuries to the Lungs: Clinical Presentation, Management and Course'. Injury, 8(1). 1-12.

Coppel D. L. (1976) 'Blast Injuries of the Lungs'. British Journal of Surgery 63, 735-7.

Gray R. C. \& Coppe D. L. (1975) 'Intensive Care of Patients with Bomb Blast and Gunshot Injuries'. British Medical Journal 270, 502-4.

Hadden W. A. Rutherford W. H. \& Merrett J. D. (1978) 'The Injuries of Terrorist Bombing: A Study of 1532 Consecutive Patients'. British Journal of Surgery 65, 525-31.

Hill J. F. (1979) 'Blast Injury with Particular Reference to Recent Terrorist Bombing Incidents'. Annals of the Royal College of Surgeons, England 61, 4-11.

Owen-Smith M. S. (1981) Explosive blast injuries. In: High Velocity Missile Wounds. Edward Arnold, London. p. 52.

Sharpe D. T., Roberts A. H. N., Barclay T. L. et al. (1985) 'Treatment of burns casualties after fire at Bradford City Football Ground'. British Medical Journal 291, 945-8. 